\title{
Effect of Particle Size on Zirconia Gel-Casting Process
}

\author{
In-Woong Kim* and Sang-Jin Lee ${ }^{*, * *, *}$ \\ *Department of Advanced Materials Science and Engineering, Mokpo National University, Muan 534-729, Korea \\ **Research Institute of Ceramic Industry and Technology, Mokpo National University, Muan 534-729, Korea
}

(Received September 2, 2015; Revised October 7, 2015; Accepted October 8, 2015)

\begin{abstract}
The fabrication process of zirconia gel-casting was studied to obtain dense zirconia on a large scale or with complicated shapes. As an experimental parameter, two different particle sizes $(0.1 \mu \mathrm{m}$ and $0.7 \mu \mathrm{m})$ of zirconia powder were applied to the gel-casting process. The viscosity behavior of slurries incorporating $40 \mathrm{vol} \%$ of zirconia powder was examined as a function of the dispersant content and the solid load to determine the optimum dispersion conditions. In addition, the gelation time with an initiator, the de-binding behavior, and the main factors affecting densification were examined. The densification of the gel-casted zirconia green body depended on the mixing ratio between the monomer and the dimer and on the zirconia particle size. A green body with a small particle size of $0.1 \mu \mathrm{m}$ showed less densification, with a relative density of $93 \%$. This may be due to the excess number of bubbles created through interactions between the larger particle surface and polymer additives during the ball-milling process.
\end{abstract}

Key words : Zirconia, Gel-casting, Particle size, Densification, Dispersion

\section{Introduction}

$\mathbf{Z}$ irconia is a heat-resistant material with the high melting temperature (about $2,700^{\circ} \mathrm{C}$ ) along with the wideranging chemical-resistant stability from acid to alkali domain, as well as excellent material properties such as low thermal conductivity, low thermal expansion, high strength, high hardness and wear resistance, etc. It is also used for automotive exhaust gas oxygen sensor, high-temperature solid electrolyte fuel cell, etc. utilizing its electrical and electromagnetic characteristics, and for wear-resistant cutting tool, grinding balls, nozzle for continuous casting, artificial jewel, etc. utilizing its mechanical and optical characteristics. Chemical characteristics are also excellent, having wide applicability such as jigs for semiconductors, carrier for catalysts, biomaterials, etc. However, its actual applications are restricted due to reliability problems caused by complicated shape manufacturing and high processing costs despite such wide applicability. Although there are forming methods such as injection molding, isostatic pressing, extrusion molding, pressure injection molding, etc. amidst the increased interest in development of processes capable of manufacturing complicated shapes, such forming methods react sensitively to slip conditions, mold retention, demolding property, machinability, etc., and show problems such as low yields of green body, long pro-

\footnotetext{
${ }^{\dagger}$ Corresponding author : Sang-Jin Lee

E-mail : lee@mokpo.ac.kr

Tel : +82-61-450-2493 Fax : +82-61-450-2498
}

cess time, density gradient, etc. ${ }^{1-3)}$

To overcome such limitations for the forming techniques, gel-casting technique has been developed. The gel-casting method has great characteristics allowing complete separation of flow process and solidification process for the slip so that not only near net shaping of complicated shapes is facilitated, but also application to manufacturing of largescale green bodies of simple form such as circle or square, etc. is possible. Also, it is characterized by being able to satisfy the demands in small quantity batch production for economic advantages since the green bodies have a high strength allowing implementation of machining. ${ }^{4)}$ Although there is a disadvantage due to complication of processes caused by addition of additional additives, gelation reaction time of the slip can be controlled to facilitate the control of forming rates. To utilize the advantages, preparation of uniform slip with dispersion in high concentrations is required, through which defects can be minimized upon drying of the green bodies and manufacturing of sintered bodies with a complicated shape is enabled. ${ }^{5)}$ Studies to prepare green bodies by gel casting using $\mathrm{Al}_{2} \mathrm{O}_{3}, \mathrm{Si}_{3} \mathrm{~N}_{4}, \mathrm{SiAlON}, \mathrm{ZrO}_{2}$ powders have been reported. Upon preparation of slurries for gel casting, the results have been reported where sintered bodies were obtained by increasing the green density with 60 vol\% for solid content of $\mathrm{Al}_{2} \mathrm{O}_{3}, 40$ vol\% for $\mathrm{Si}_{3} \mathrm{~N}_{4}$, and 55 vol\% for SiAlON. ${ }^{6,7)}$ In the case of alumina gel casting, production of the slurries with $59 \mathrm{vol} \%(4.63 \mu \mathrm{m}), 57 \mathrm{vol} \%$ $(0.32 \mu \mathrm{m})$ of solid contents was possible using alumina raw materials of different particle sizes. The maximum relative densities obtained from the prepared green bodies were $58.9 \%(4.63 \mu \mathrm{m}), 60 \%(0.32 \mu \mathrm{m})$, and a study was reported 
where the dry shrinkage rates were increased, the finer the starting particle sizes, and the lower the solid contents of the slip. ${ }^{5)}$ On the other hand, almost no study results are obtained on gel casting using zirconia, and consequently, studies on gel casting concerning the zirconia used for diversified applications are deemed necessary. ${ }^{8)}$

In the present study, the gel casting behavior of zirconia has been considered using the existing gel-casting forming method. Each gel green body was prepared by using two kinds of zirconia with different particle sizes, and their material properties were compared. Major process variables required here such as slurry dispersion and optimum solid content, adequate forming time and de-binding condition, etc. were considered through experiments. In addition, the effects of such process variables on the final green body and the sintered body were considered.

\section{Experimental Procedure}

\subsection{Starting raw materials}

As the starting raw materials, zirconia powder ZL-3YA (Changsha Zhonglong Chemical Co., China, average particle diameter : $\sim 0.7 \mu \mathrm{m}, \mathrm{BET}: 8.9 \mathrm{~m}^{2} / \mathrm{g}, \quad \mathrm{Y}_{2} \mathrm{O}_{3}$ content of 5.5wt\%) and TZS3Y (Sin Xing Advanced Material Limited., Hong Kong, average particle diameter : $\sim 0.1 \mu \mathrm{m}$, BET : $15.2 \mathrm{~m}^{2} / \mathrm{g}, \mathrm{Y}_{2} \mathrm{O}_{3}$ content of $5.23 \mathrm{wt} \%$ ) were used, while SNDispersant 5468 (San nopco, Korea) was used as the zirconia slurry dispersant. As the organic monomer, acrylamide (AM, $\left(\mathrm{H}_{2} \mathrm{C}=\mathrm{CHCONH}_{2}\right.$; Daejung Chemical Co., Korea) of mono-functional type was used, while ethylenbisacrylamide (MBAM, $\left(\mathrm{C}_{2} \mathrm{H}_{3} \mathrm{CONH}\right)_{2} \mathrm{CH}_{2}$, Sigma) was used as the dimer for the bi-functional type of cross-linking agent. As the initiator and the catalyst for polymerization, ammonium persulfate (APS, $\left(\mathrm{NH}_{4}\right)_{2} \mathrm{~S}_{2} \mathrm{O}_{8}$, Daejung) and N,N,N',N'-Tetramethylendiamine (TEMED, $\left(\mathrm{CH}_{3}\right)_{2} \mathrm{NCH}_{2} \mathrm{CH}_{2} \mathrm{~N}\left(\mathrm{CH}_{3}\right)_{2}$, Daejung) were used, respectively.

\subsection{Preparation of gel green body and sintering}

To find the optimum dispersion conditions for zirconia slurry, zirconia powder was placed in distilled water, mixed with dispersant for dispersion in a polyethylene bottle by ball milling for $24 \mathrm{~h}$ using zirconia balls, followed by measurement of viscosity for each slurry. Optimum dispersion conditions were considered by fixing the solid content of each zirconia powder at $40 \mathrm{vol} \%$ and controlling the amount of dispersant. Subsequently, dispersion behavior was observed while the solid content of zirconia was additionally added for an increase in the green density. Monomer, dimer, initiator and catalyst were added to each of zirconia slurries finally prepared by control of the solid content and the added amount of dispersant, with the added amounts shown in Table 1. Since the slurry which underwent the second ball milling process after addition of organics had many bubbles which were removed by using a vacuum pump while rotating the slurry with a magnetic stirrer. Upon defoaming process, the defoaming time was fixed at 3 minutes, and the
Table 1. Mixing Content of Addition for Gel Casting

\begin{tabular}{ccc}
\hline Addition & Classification & $\mathrm{wt} \%$ \\
\hline Acrylamide & monomer & 2.0 \\
N,N'-methylen bisacrylamide & dimer & 0.1 \\
Ammonium persulfate & initiator & 0.1 \\
N,N,N',N'-Tetra methylendiamine & catalyst & 0.01 \\
\hline
\end{tabular}

initiator was added by varied amounts of $0.01 \mathrm{wt} \%$ $0.05 \mathrm{wt} \%$ before the slurry was poured into the mold, while a stirrer was employed to prevent occurrence of slurry agglomeration. The stirring time was fixed at 2 minutes. An acrylic mold (50mm in diameter, $40 \mathrm{~mm}$ in thickness) was filled with the slurry, and the gelation reaction time was controlled to be 15 20 minutes. After all gelation was processed, it was demolded and subsequent drying was conducted through 3 stages at $20^{\circ} \mathrm{C}$ for $24 \mathrm{~h}$, at $80^{\circ} \mathrm{C}$ for $24 \mathrm{~h}$, and finally at $120^{\circ} \mathrm{C}$ for $24 \mathrm{~h}$ under a given humidity (40\%). The dried gel green body was subjected to calcination based on the thermogravimetric analysis results, and sintered at the general sintering temperature for zirconia of $1480^{\circ} \mathrm{C}$ while being held for $2 \mathrm{~h}$.

\subsection{Characteristics analysis}

Slurry viscosities were measured using a rotary viscometer (DV-I Prime, Brookfield, USA) with the shear rate fixed at $100 \mathrm{rpm}$, as a function of the solid content of zirconia powder and the amount of dispersant. Sintered densities for the densified specimens were measured by using Archimedes principle, while densities of the gel-type green body were measured by calculation after measurement of weight and volume of the green body. In thermal analysis of the gel-type green body, weight reduction and thermal change were measured using TG-DTA (Perkin Elmer, STA-6000). Each microstructure of the green body and the sintered body was observed using a FE-SEM (JEOL, JSM-7100F). After the formed and sintered zirconia specimens were coated with Au-Pd sputter, fractured surfaces of each specimen were observed.

\section{Results and Discussion}

\subsection{Viscosity behavior of slurry}

Optimum slip conditions were considered by observation of viscosity changes resulting from addition of the dispersant to the slip dispersed in high concentrations, according to the report that monomer and dimer had almost no effects on dispersion of ceramic particles upon preparation of the slip consisting of zirconia powder and distilled water as a dispersion medium, dispersant, monomer and dimer. ${ }^{5)}$

In Fig. 1, viscosity changes for the zirconia slurry are shown as a function of the added amount of dispersant. In the case of ZL-3YA powder, the lowest viscosity value of 230 $\mathrm{cP}$ was observed at $1.6 \mathrm{wt} \%$ according to the measurement results for each viscosity value while the added amounts of dispersant were varied between $1.2 \sim 2.0 \mathrm{wt} \%$ for applica- 


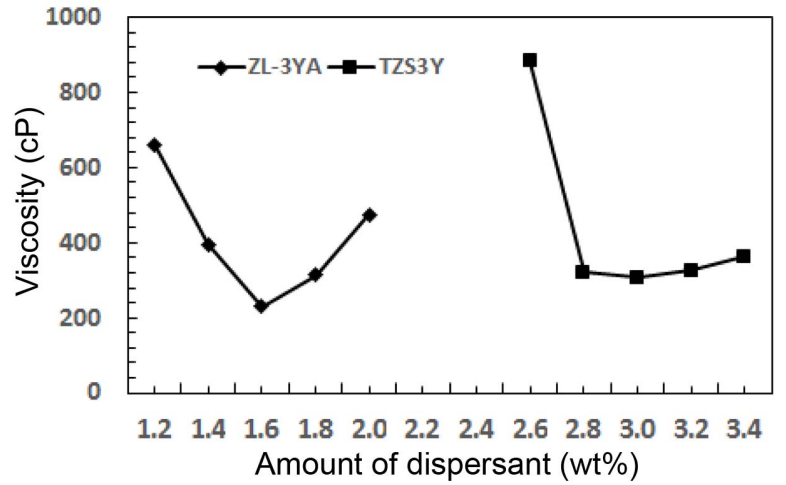

Fig. 1. Effect of dispersant content on viscosity of zirconia slurry.

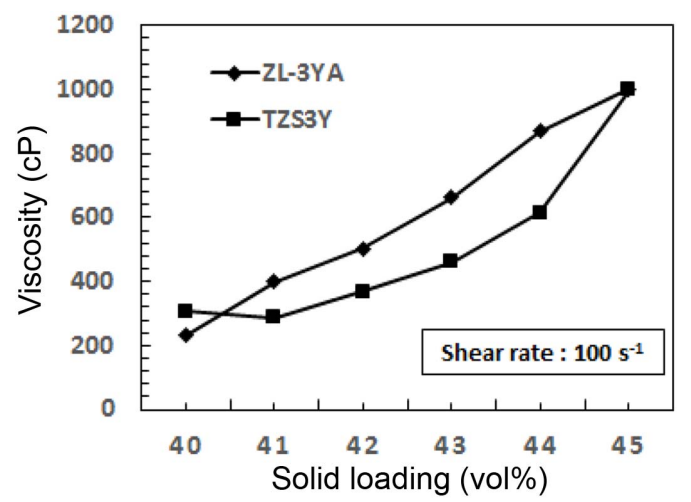

Fig. 2. Viscosity of zirconia slurry depending on solid loading.

tion. In TZS3Y powder, viscosity values were measured while the amounts of dispersant were varied between $2.6 \sim$ $3.2 \mathrm{wt} \%$, and the lowest viscosity value of $306 \mathrm{cP}$ was observed at $3.0 \mathrm{wt} \%$. In the case of TZS3Y, dispersion was made possible by increasing the amount of dispersant as no dispersion was realized when dispersion was attempted in the same way for the small amount of dispersant at $1.2 \sim$ $2.0 \mathrm{wt} \%$. Since the particles of TZS3Y powder were fine as compared with the particles of ZL-3YA, the specific surface area of the particles was large so that the adsorbed amount of polymer electrolyte was increased. When the amount of dispersant was smaller than $1.6 \mathrm{wt} \%$, ZL-3YA powder exhibited very high viscosities, suggesting that dispersion stability was lacking since the amount of dispersant adsorbed to zirconia particle surfaces and the surface charge required for dispersion were insufficient. Meanwhile, somewhat high viscosities were also exhibited for the amounts higher than $1.6 \mathrm{wt} \%$, suggesting that extra dispersant left after adsorption of the added dispersant onto zirconia surfaces contributed rather to an increase in viscosities of the slurry as the extra dispersant was dissolved in the dispersion medium of water to induce osmotic pressures. ${ }^{9)}$ In each case, viscosity changes were measured as a function of the increase in solid contents for zirconia powder, based on the conditions to obtain the lowest viscosity. Viscosities were measured while the solid contents were varied between 40 vol\% $\sim 45$ vol\%, with the results shown in Fig. 2 . Bowen ${ }^{10)}$ has shown that ceramic particles dispersed in high solid contents enable preparation of uniform green bodies having a high green density upon forming process so as to be able to reduce the sintering times and lower the sintering temperatures upon sintering. Zirconia gel-casting slurries were prepared by finally fixing the solid contents for zirconia at $40 \mathrm{vol} \%, 41 \mathrm{vol} \%$ as the lowest viscosities were observed at $40 \mathrm{vol} \%$ for ZL-3YA powder and at $41 \mathrm{vol} \%$ for TZS3Y according to the measurement results. While the optimum viscosity could be found even above $50 \mathrm{vol} \%$ in terms of the solid contents for alumina gel-casting, ${ }^{11)}$ the fact that a lower solid content was applied in the case of zirconia as compared with alumina is considered to be a phenomenon caused by the relatively higher density compared with that of alumina.

\subsection{Gelation reaction behavior as a function of the amount of reaction initiator}

Although polymerization reaction for conversion of monomers to polymer takes place as a result of addition of the reaction initiator, gelation does not occur as yet the viscosity is low in the first stage of polymerization characterized by a low molecular weight. In the second stage after passing through such gelation reaction section, the phenomenon is exhibited where the molecular weights are drastically increased by autoaccelation when a given conversion rate is exceeded. In the last stage, the phenomenon is observed where the degree of polymerization is saturated or reduced again, while a high viscosity is maintained. Therefore, to apply polymerization reaction to gel-casting, the gel-casting should be completed in the first stage having no occurrence of the gelation, and appropriate control of the gelation reaction times is very important for establishment of the reproducible gel-casting process. ${ }^{7}$ In Fig. 3, changes in the gelation reaction times at room temperature are shown as a function of the amount of reaction initiator added to the zirconia slurry. As the added amounts of reaction initiator were increased, the gelation reaction time could be seen to be shortened. This is attributed to acceleration of radical

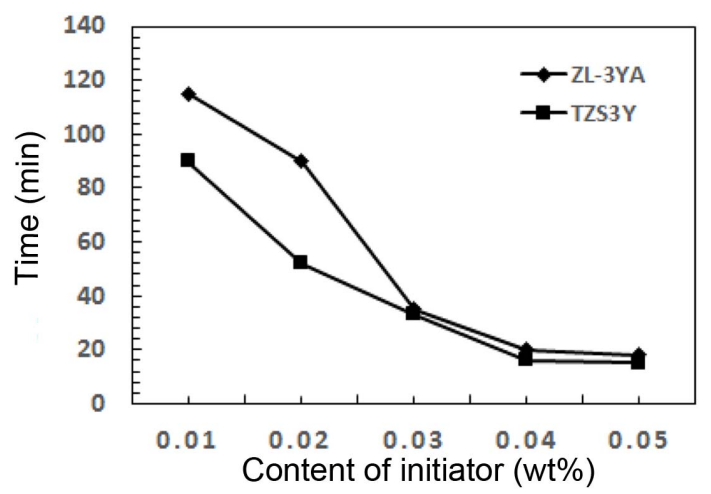

Fig. 3. Gelation time depending on initiator content. 
generation rates by activation of the catalyst as the amounts of initiator were increased upon polymerization, while the gelation reaction times are sensitively affected by the amount of initiator rather than the amount of catalyst which is attributable to the fact that the rate of polymerization reaction is determined as the catalyst is dependent on the initiator. When only the initiator is added, the gelation reaction time is known to be extended very much to about $50 \mathrm{~h}^{12)}$ In the present study, the gelation reaction time of about 30 minutes was to be secured for smooth gel-casting. When the particle sizes of zirconia powder were small, the gelation time was shortened upon addition of the same amount of initiator, and about 30 minutes of gelation reaction time could be obtained upon addition of about $0.03 \mathrm{wt} \%$ of the initiator.

\subsection{De-binding and sintering behavior}

As a process to remove residual water in the drying process and organic polymer which forms the structure of green body, calcination process in air atmosphere is required, and thermal analysis of each gel-type green body was conducted to find the optimum calcination process. As shown in Fig. 4, weight reduction began to be observed as the residual water was removed around $100^{\circ} \mathrm{C}$ in the case of ZL-3YA powder, and drastic weight reduction was realized along with exothermic reaction as the organics inside green body underwent de-binding between $300^{\circ} \mathrm{C}$ and $450^{\circ} \mathrm{C}$. In the case of TZS3Y powder, weight reduction was exhibited twice around $300^{\circ} \mathrm{C}$, with the de-binding being realized at a lower temperature compared with ZL-3YA powder. In both samples, de-binding continued to occur up to $900^{\circ} \mathrm{C}$, and based on such de-binding behavior it was heat treated up to $1000^{\circ} \mathrm{C}$ at a slow temperature rise rate of $0.5^{\circ} \mathrm{C} / \mathrm{min}$, and

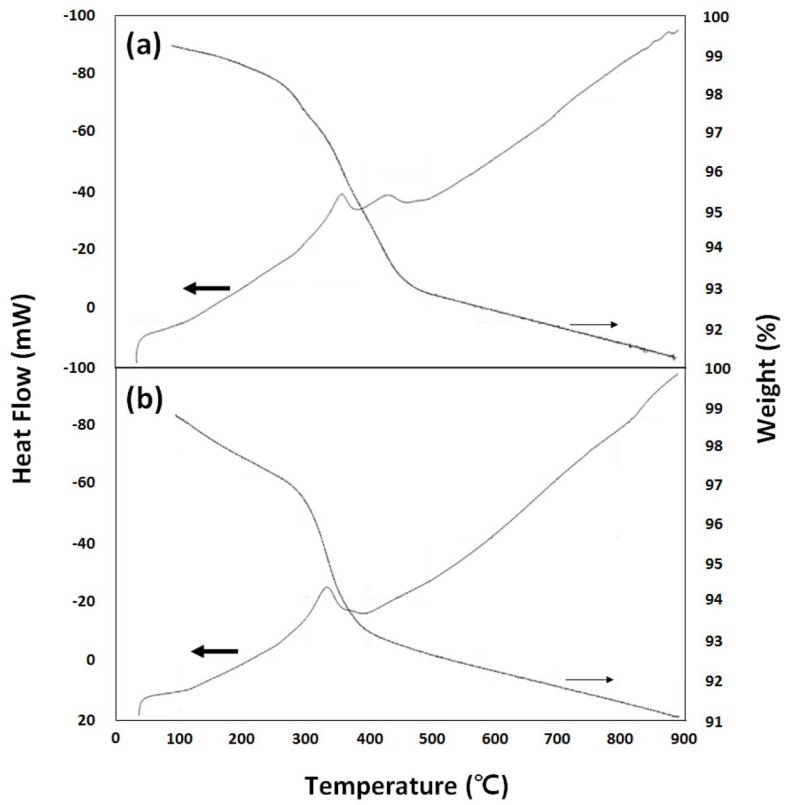

Fig. 4. TG-DTA curves of gel-casted zirconia green body (a) ZL-3YA, (b) TZS3Y. subjected to continuous temperature rise up to $1480^{\circ} \mathrm{C}$ which was held for $2 \mathrm{~h}$ for sintering.

Microstructures after sintering are shown in Fig. 5. Relative densities measured after sintering of the green bodies prepared by mixing with $0.05 \mathrm{wt} \%$ of initiator were shown to be $97 \%$ and $93 \%$ for ZL-3YA powder and TZS3Y powder, respectively. Sintering shrinkages for both cases were shown to be similar at about $29 \%$, and no exaggerated grain growth was observed in either case. In TZS3Y powder with smaller particle sizes than ZL-3YA powder, distribution of many pores could be observed, where the effects of the mixing ratio for monomer, dimer as well as the bubbles produced during process, etc. were considered to be the main factor, and such factors are considered to have been affected by interaction with the particle sizes of the zirconia powder used.

\subsection{Discussion on mixing ratio for monomer, dimer and bubble production}

Effects of the mixing ratio for monomer, dimer on sintering of zirconia have been considered. Shown in Fig. 6 are the changes in sintered density of ZL-3YA powder and TZS3Y powder as a function of the mixing ratio for monomer and dimer. Difference in the sintered densities between the two powders occurred as the mixing ratio for monomer was increased. In the case of TZS3Y powder, the density was decreased as the mixing ratio for monomer was increased due to fine particle sizes. This is considered to have resulted from occurrence of agglomerate formation during the process where spaces without combination of monomers and
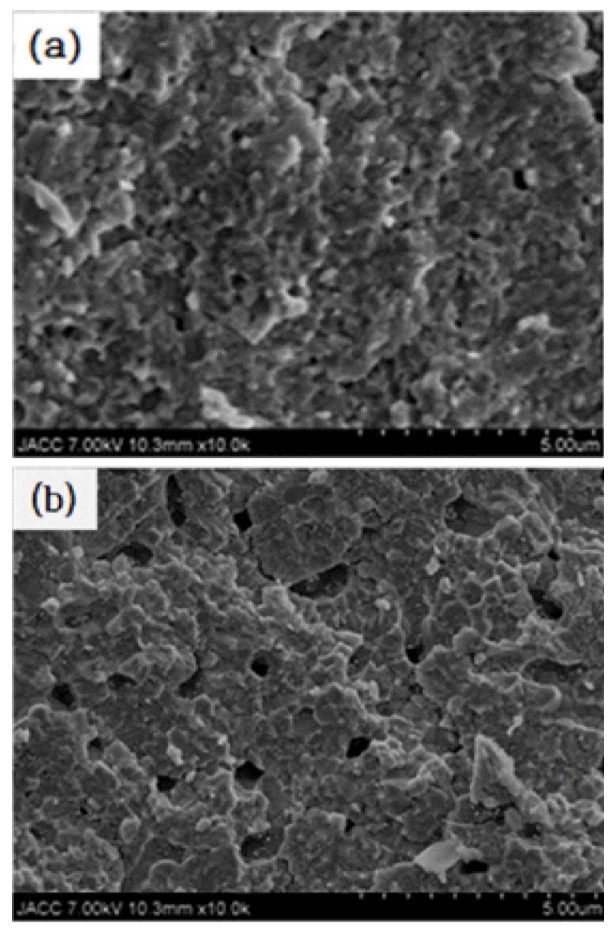

Fig. 5. SEM micrographs of gel-casted zirconia sintered at $1480^{\circ} \mathrm{C}$ for $2 \mathrm{~h}$; (a) ZL-3YA, (b) TZS3Y. 


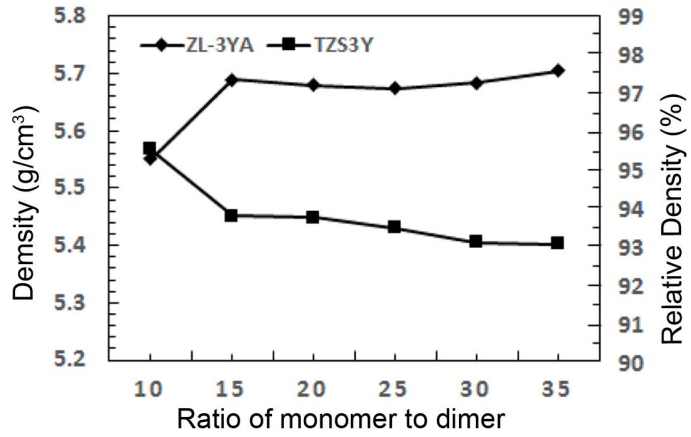

Fig. 6. Variation of sintering density according to mixing ratio of monomer and dimer.
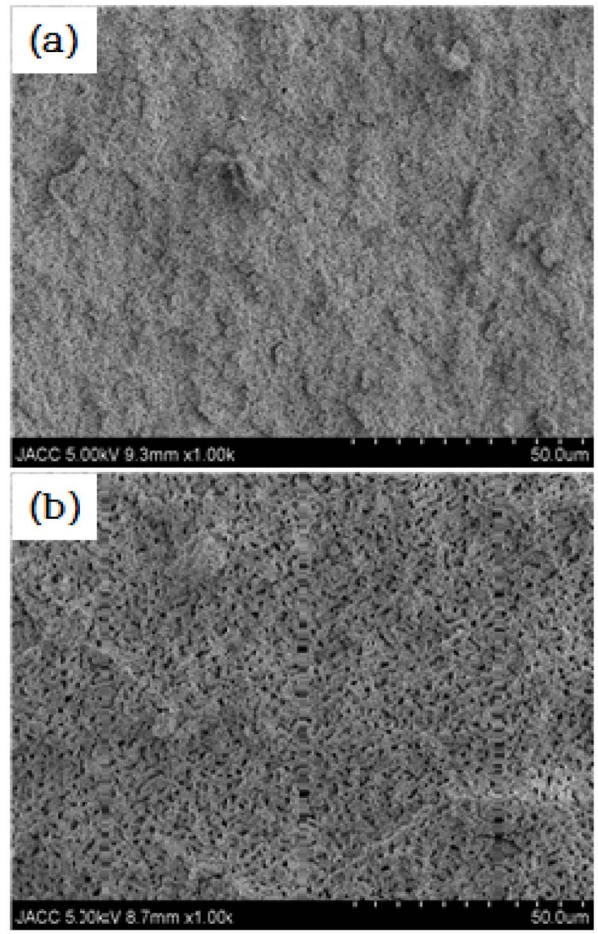

Fig. 7. SEM micrographs of gel-casted zirconia green body (a) ZL-3YA, (b) TZS3Y.

dimers as only the amount of monomers was increased while the amount of dimers was fixed during the mixing process of fine particles, monomers and dimers.

Occurrence of a difference in residual bubbles could be seen from the measurement of differences in the density of gel green bodies, although all of the prepared gel slurries underwent a given defoaming process. In the case of gel green bodies prepared with ZL-3YA powder, the higher density of $49 \%$ was measured, which was higher than that for the gel green body prepared with TZS3Y powder (relative density of $45 \%$ ). Such difference in the density of green bodies is considered to occur due to interaction between the powder and the additives caused by a difference in the specific surface areas. Namely, while undergoing ball-milling process after addition of organics such as monomer, etc. for gel formation, it is considered that bubbles were produced by reaction between these additives and the particle surfaces of zirconia powder, and relatively more bubbles were produced in the gel slurry when particle sizes were small. Some residual bubbles were left behind even after defoaming due to a high viscosity of the slurry which is considered to have acted as the cause for bubble production upon sintering. Microstructure of the green body is shown in Fig. 7. In the case of gel green body prepared with TZS3Y powder, presence of fine pores could be affirmed.

\section{Conclusions}

In the present study, green bodies were prepared by gelcasting process with zirconia of different particle sizes as the starting material, and viscosity behavior as well as gelation behavior as a function of dispersant, solid content, organic additives, etc. and the effects on sintering thereof have been considered. To prepare the slip of high solid content having optimum dispersion conditions, about twice as much dispersant was applied to the slurry made of fine powder of $0.1 \mu \mathrm{m}$ in size compared with the slurry made of powder of $0.7 \mu \mathrm{m}$ in size. Gelation reaction time was reduced according to the added amount of initiator irrespective of particle sizes, and the sintered density was decreased in the case of powder of $0.1 \mu \mathrm{m}$ in size as the added amount of monomer was increased in comparison with that of dimer. Contrary to the theory that sinterability is improved for fine powders, more bubbles were produced in the microstructure of sintered body, resulting in relatively low sintered densities, when the starting particles of zirconia were small at $0.1 \mu \mathrm{m}$ in size. This is considered to be the result of production of many pores due to interaction between the high surface areas of the organic additives and the powder upon mixing process by ball-milling.

\section{REFERENCES}

1. O. O. Omatete, M. A. Janney, and S. D. Nunn, "Gelcasting : From Laboratory Development Toward Industrial Production," J. Eur. Ceram. Soc., 17 [2-3] 407-13 (1997).

2. D. W. Richerson, Modern Ceramic Engineering; pp. 178216, Marcel Dekker, New York, 1982.

3. J. F. Young, R. S. Shane, Material and Processes; pp. 14411472, Marcel Dekker, New York, 1984.

4. B. H. Ryu, J. W. Kim, D. J. Kim, and J. D. Lee, "Effect of Organic Additives on Fluidity of Gel casting Ceramic Slip," Theories and Applications of Rheology, 4 [1] 100-3 (2000).

5. C. G. Ha, J. W. Kim, C. Y. Jo, U. G. Paik, and Y. G. Jung, "Effects of Particle Size on Processing Variables and Green Microstructure in Gelcast Alumina Green Bodies," Korean J. Mater. Res., 11 [10] 869-78 (2001).

6. O. O. Omatete and A. Bleier, "Tailoring Suspension Flow for the Gelcasting of Oxide and Nonoxide Ceramics," Mat. Res. Soc. Symp. Proc., 346 357-63 (1994).

7. A. Bleier, O. O. Omatete, and C. G. Westmoreland, "Rheology of Zirconia-Alumina Gelcasting Slurries," Mat. Res. Soc. Symp. Proc., 271 269-75 (1992). 
8. S. E. Yun, S. K. Woo, K. Bae, and D. P. Kim, "Effect of Chemical Parameters on Aqueous Acrylamide Gelcasting," J. Korean Ind. Eng. Chem., 10 [5] 748-53 (1999).

9. T. A. Ring, Fundamentals of Ceramic Powder Processing and Synthesis; Vol. 10, pp. 421-493, Academic Press, Utah, 1996.

10. A. Roosen and H. K. Bowen, "Influence of Various Consolidation Techniques on the Green Microstructure and Sinter- ing Behavior of Alumina Powders," J. Am. Ceram. Soc., 71 [11] 970-77 (1988).

11. C. J. Oh and H. L. Lee "Microstructures and Drying of the Alumina Green Body by the Gel-Casting Method," $J$. Korean Ceram. Soc., 31 [12] 1467-74 (1994).

12. A. C. Young, O. O. Omatete, M. A. Janney, and P. A. Menchhofer, "Gelcasting of Alumina," J. Am. Ceram. Soc., 74 [3] 612-18 (1991). 